\title{
Validity of an adapted Household Food Insecurity Access Scale in urban households in Iran
}

\author{
Fatemeh Mohammadi ${ }^{1}$, Nasrin Omidvar ${ }^{1, *}$, Anahita Houshiar-Rad ${ }^{2}$, \\ Mohammad-Reza Khoshfetrat ${ }^{3}$, Morteza Abdollahi ${ }^{2}$ and Yadollah Mehrabi ${ }^{4}$ \\ 'Department of Community Nutrition, National Nutrition and Food Technology Research Institute, Faculty of \\ Nutrition Sciences and Food Technology, Shahid Beheshti University of Medical Sciences, PO Box 19395-4741, \\ Tehran, Iran: ${ }^{2}$ Department of Nutrition Research, National Nutrition and Food Technology Research Institute, \\ Faculty of Nutrition Sciences and Food Technology, Shahid Beheshti University of Medical Sciences, Tehran, \\ Iran: ${ }^{3}$ Department of Food and Nutrition Policy and Planning Research, National Nutrition and Food Technology \\ Research Institute, Faculty of Nutrition Sciences and Food Technology, Shahid Beheshti University of Medical \\ Sciences, Tehran, Iran: ${ }^{4}$ Department of Biostatistics, Faculty of Public Health, Shahid Beheshti University of \\ Medical Sciences, Tehran, Iran
}

Submitted 3 November 2010: Accepted 10 May 2011: First published online 2 August 2011

\begin{abstract}
Objective: To assess the validity of a locally adapted Household Food Insecurity Access Scale (HFIAS) in the measurement of household food insecurity (FI) in the city of Tehran.

Design: A cross-sectional study.

Setting: Urban households were selected through a systematic cluster sampling method from six different districts of Tehran. The socio-economic status of households was evaluated using a questionnaire by means of interviews. An adapted HFIAS was used to measure FI. Content validity was assessed by an expert panel, and the questionnaire was then tested among ten households for clarity. Criterion validity was assessed by comparing the measure with a number of determinants and consequences of FI. Internal consistency was evaluated by Cronbach's $\alpha$ and exploratory factor analysis. For repeatability, the questionnaire was administered twice to twenty-five households at an interval of $20 \mathrm{~d}$ and Pearson's correlation coefficient was calculated.

Subjects: A total of 416 households.

Results: In all, $11 \cdot 8 \%, 14 \cdot 4 \%$ and $17 \cdot 5 \%$ of the households were severely, moderately and mildly food insecure, respectively. Cronbach's $\alpha$ was 0.855. A significant correlation was observed between the two administrations of the questionnaire $(r=0.895, P<0 \cdot 001)$. Factor analysis of HFIAS items revealed two factors: the first five items as factor 1 (mild-to-moderate FI) and the last four as factor 2 (severe FI). Heads of food-secure households had higher education and higher job position compared with heads of food-insecure households $(P<0 \cdot 001)$. Income and expenditure were lower in food-insecure households compared with food-secure households.

Conclusions: Adapted HFIAS showed acceptable levels of internal consistency, criterion validity and reliability in assessing household FI among Tehranians.
\end{abstract}

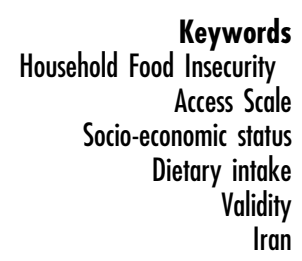

Food security is attained when all people have physical and economic access to sufficient food at all times to meet their dietary needs for a productive and healthy life ${ }^{(1,2)}$. This is a complex, multidimensional concept; thus, measuring food insecurity (FI) has been an ongoing challenge for researchers and practitioners. However, the issue remains important as hundreds of millions of individuals and households are affected on a daily basis in both the developing and developed world. Measuring food security at national, regional, community and household levels is important for developing appropriate policy and programme options $^{(3,4)}$. There is a need to improve the tools and frameworks for targeting various interventions (especially for the vulnerable segments of a population) to achieve optimum resource allocation.

To respond to this need, the Food and Nutrition Technical Assistance (FANTA) project of the US Agency for International Development developed the Household Food Insecurity Access Scale (HFIAS), which is an adaptation of the eighteen-item Household Food Security 
Survey Module (HFSSM) used by the US Department of Agriculture (USDA) and other US agencies to measure the access component of FI in the USA. The HFSSM approach is based on the idea that experience of FI causes predictable reactions that can be captured through a survey and summarized on a scale. Respondents are asked directly whether the household has experienced conditions typical of a food-insecure household during a specified recall period, including experiences related to anxiety about the household's food supply, insufficient quality of food, food intake and the physical consequences. Sometimes referred to as an 'experiential' or 'perception-based' method of collecting data on FI, this approach has been used by USDA to monitor food assistance programmes and to estimate the prevalence of FI since 1995, and has consistently been validated as a statistically meaningful measure of FI in the $\mathrm{USA}^{(5,6)}$.

Because of the complex, multidimensional nature of FI and the strong subjective element to this construct, it is difficult to identify a simple 'gold standard' against which FI scales can be validated. Instead, validity needs to be examined from a variety of perspectives ${ }^{(7)}$. The most common Household Food Security questionnaire validation studies have been conducted using criterion validity, Rasch modelling and Cronbach's $\alpha$ coefficient. Content validity is also implied by the fact that the performance of these instruments is consistent with the understanding of FI that has arisen from qualitative research ${ }^{(8,9)}$. Specifically, factor analysis of questionnaire responses confirms the conceptual components of FI as these have been theorized from qualitative research ${ }^{(10,11)}$. The item response pattern (i.e. the sequence of affirmative responses among model households) is consistent with the understanding of FI as a managed process ${ }^{(9,12)}$.

Criterion validity refers to the correlation of the scale with a large number of determinants and consequences of the phenomenon, such as income, education, participation in food assistance programmes, having savings, food expenditure and food consumption ${ }^{(9)}$.

In Iran, on the basis of the Household Expenditure and Budget Survey data of 2005, 20\% of households have been deemed food insecure, in that they are estimated to have access to $<90 \%$ of their dietary energy needs, and $11 \%$ have been deemed severely food insecure with access to $<80 \%$ of energy needs ${ }^{(13-17)}$. Thus, the need for a valid and reliable tool that can be easily used at the field level has long been felt in the country. To date, three validation studies have been carried out on FI questionnaires in the country. Zerafati et al. ${ }^{(18)}$ modified the Radimer/Cornell questionnaire to measure FI in low-income urban households in Tehran. They found high levels of FI in the sample (27\% household FI, 37\% adult FI and 19\% child hunger) and some support for the validity and reliability of the instrument. Dastgiri et al. ${ }^{(19)}$ evaluated the sensitivity and specificity of the short-form (six items) questionnaire for screening of FI in the north-west of Iran, compared with the adequacy of energy and four key nutrients. Rafiei et al. ${ }^{(20)}$ assessed the internal validity of the adapted US HFSSM to measure FI among adults and children in Isfahan, central Iran, using statistical methods based on the Rasch measurement model. They found $45 \cdot 8 \%$ and $47 \cdot 8 \%$ FI among adults and children, respectively.

The HFSSM has generated considerable interest throughout the developing world and was adapted as a food security measurement tool in some countries ${ }^{(21)}$, including Iran. However, HFIAS, which is based on the universal experience of the access component of household FI across countries and cultures ${ }^{(22)}$, may be more suitable for measuring FI in the country than the US HFSSM and other previously developed tools. Therefore, it is critical for researchers, policy makers, governmental and non-governmental agencies and all interested sectors to invest time and resources in the process of developing such tools that provide valid and reliable measures of food security in Iran. In the present study, we assessed the validity of a locally adapted HFIAS to measure household FI in the city of Tehran.

\section{Materials and methods}

The present study was conducted in the framework of Measurement and Modeling of Food Security in Urban Households in the city of Tehran during 2009-2010. Households were selected from six districts (out of twentytwo districts in Tehran) by means of a systematic cluster sampling method. The districts were chosen on the basis of the socio-economic status (SES) of residents in the city municipality. As the highest SES groups in Tehran are residents of districts 1-3, approximately one-third of the studied households were chosen from these districts. The same approach was adopted to classify districts 10 and 12 as medium SES (middle income) and districts 18 and 20 as low-SES districts. With respect to the $22 \%$ estimated prevalence of FI in $\operatorname{Iran}^{(16)}$, a sample size of 400 households was estimated. The number of households in each district was determined on the basis of their population.

Interviewers participated in a $1 \mathrm{~d}$ workshop to reduce variations and to familiarize them with field lessons on FI data gathering. The study was conducted after obtaining informed consent from both the head of each household and the person responsible for food preparation (mainly the wife). At the end of each interview, a gift with the logo of the National Nutrition and Food Technology Research Institute was provided to the household or respondent.

Data on demographics and SES of each household were obtained through interviews using a questionnaire that included sociodemographic variables, including age, sex, educational and occupational levels of the head and other members of the household, size of family, income, expenditure and some characteristics of residency and living conditions. 
Dietary intake was assessed by trained nutritionists using three consecutive $24 \mathrm{~h}$ dietary recalls (two ordinary and one holiday) completed by the person responsible for food preparation (mainly the wife). The revised edition of the Iranian food composition table was used to calculate the intake of nutrients. The mean intake of food groups for each female participant as the average of the entire amount consumed during the $3 \mathrm{~d}$ of interview was calculated.

To measure FI, the HFIAS was locally adapted through several steps. After translating it into Farsi, content validity was assessed by a panel consisting of experts on FI. The questionnaire was then tested among ten households for clarity. The final tool was translated back into English and sent back to FANTA researchers. The meaning of the original HFIAS questions appeared similar in most cases. Final refinements were made on the basis of the recommendations of the FANTA researchers, and they took the opportunity to update us on the most recent research findings of FANTA-2 related to the HFIAS. The modifications made included adding some examples of low-price foods such as boiled potatoes and eggplant to items 3 and 4 ; in item 3, 'eat just a few kinds of food day after day' was replaced with 'to repeat eating only a few foods for a few days', and in several items 'lack of resources' was replaced with 'not having enough money'.

Criterion validity was assessed by comparing the measure with a number of determinants and consequences of FI, including income, education and occupation of the household head. Internal consistency and construct validity of the scale were evaluated by Cronbach's $\alpha$ and exploratory factor analysis, respectively. For repeatability, the questionnaire was administered in twenty-five households twice at an interval of $20 \mathrm{~d}$ and a Pearson correlation coefficient was calculated.

\section{Statistical analyses}

The HFIAS scores categorized households into four levels of household FI: food secure, mildly insecure, moderately insecure and severely food insecure. The level of household FI was determined on the basis of the number of affirmative responses they had provided to statements on more severe conditions and/or experiences ${ }^{(5)}$.

Statistical analyses were performed using the Statistical Package for the Social Sciences statistical software package version $17 \cdot 0$ (SPSS Inc., Chicago, IL, USA), the $\chi^{2}$ test, oneway ANOVA, principal component factor analysis with Varimax rotation, Cronbach's $\alpha$ and Pearson's correlation.

\section{Results}

Out of 416 studied households, $11 \cdot 8 \%, 14 \cdot 4 \%$ and $17 \cdot 5 \%$ were severely, moderately and mildly food insecure, respectively. Figure 1 shows the frequency of household FI in the six selected districts of Tehran. No significant difference was observed in the frequency of food security between districts 1 and 3 (affluent) and between districts

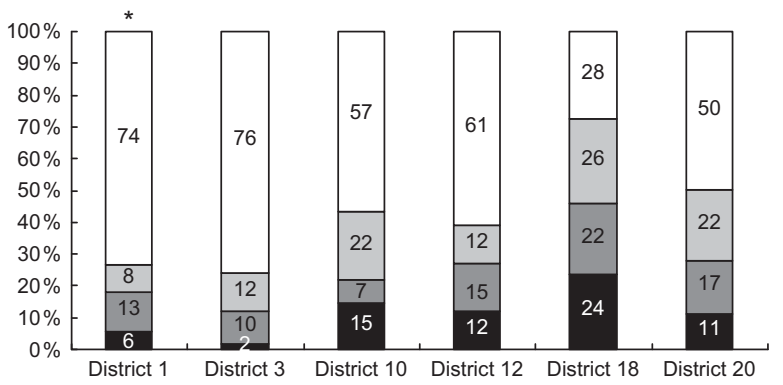

Fig. 1 Prevalence of mild, moderate and severe food insecurity in different districts of Tehran (*significant difference between districts at $P<0.001 ; \square$, food secure; $\square$, mildly insecure; $\square$, moderately insecure; $\square$, severely insecure)

10 and 12 (middle class); however, district 18 was significantly different from district 20, whereas district 20 was similar to the middle class districts (10 and 12). As shown in Fig. 1, districts 1 and 3 were significantly different from the other four districts with regard to different levels of FI (mild, moderate and severe; $P<0 \cdot 001$ ).

The mean number of rooms and area of the house, as well as income and expenditure, especially food expenditure, were lower in food-insecure households than in foodsecure households (Table 1). The high amount of other expenditure for those severely food insecure can be attributed to expenses such as medical expenses due to lack of medical insurance or their very limited coverage. In the highSES groups in Iran, having income from sources other than the main job is very common. Examples of such sources are rent from tenements or income from other assets.

Female- and male-headed households were not significantly different with regard to FI status; however, severe FI was more frequent in female-headed households. Heads of food-secure households had higher educational level and job status compared with heads of food-insecure households $(P<0 \cdot 001$; Table 2$)$.

Possession of most of household facilities (including car, cell phone, freezer, oven, automatic washing machine, vacuum cleaner, tape recorder, video/compact disc player, computer and Internet, except for stove and semi-automatic washing machine) was indicative of household food security (see Table 3).

Consumption of bread and cereals, legumes and sugar (and, marginally, fats and oils) was lower and that of fruit, milk and dairy products (and, marginally, meat) was higher in food-secure households than in food-insecure households. Mean intakes of vitamins $\mathrm{C}$ and A were higher and those of carbohydrate and thiamin were lower in food-secure households compared with food-insecure households. Energy and protein intakes were not different between households with different FI status (Table 4).

Findings from responses to each question of HFIAS are presented in Table 5. Of the nine items, the highest proportion of participants reported being 'unable to eat preferred foods', that they 'eat just a few kinds of foods' 
Table 1 Mean and SE of age of the household head, family size, area of the house, number of rooms, expenditure and income of Tehranian households based on food security status

\begin{tabular}{|c|c|c|c|c|c|c|c|c|}
\hline \multirow[b]{2}{*}{ Variable } & \multicolumn{2}{|c|}{$\begin{array}{l}\text { Food secure } \\
\quad(n \text { 222) }\end{array}$} & \multicolumn{2}{|c|}{$\begin{array}{l}\text { Mildly insecure } \\
\qquad(n 72)\end{array}$} & \multicolumn{2}{|c|}{$\begin{array}{l}\text { Moderately insecure } \\
\qquad(n 58)\end{array}$} & \multicolumn{2}{|c|}{$\begin{array}{l}\text { Severely insecure } \\
(\text { ( } 46)\end{array}$} \\
\hline & Mean & SE & Mean & SE & Mean & SE & Mean & SE \\
\hline Age of the household head (years) & $50 \cdot 5$ & 0.9 & $50 \cdot 3$ & $1 \cdot 8$ & $47 \cdot 1$ & $2 \cdot 0$ & $48 \cdot 6$ & $2 \cdot 0$ \\
\hline Family size $(n)$ & $3 \cdot 8$ & $0 \cdot 1$ & $3 \cdot 7$ & $0 \cdot 2$ & $3 \cdot 9$ & $0 \cdot 2$ & $3 \cdot 9$ & 0.2 \\
\hline Area of the house $\left(\mathrm{m}^{2}\right)$ & $115 \cdot 7$ & $4 \cdot 2$ & $82 \cdot 7^{\star \star \star}$ & $4 \cdot \overline{4}$ & $92 \cdot 0^{\star \star \star}$ & $9 \cdot \overline{6}$ & $82 \cdot 1^{\star \star \star}$ & $6 \cdot \overline{7}$ \\
\hline Number of rooms & $2 \cdot 96$ & 0.07 & $2 \cdot 55^{\star \star \star}$ & $0 \cdot 11$ & $2 \cdot 39^{\star \star \star}$ & $0 \cdot 12$ & $2 \cdot 47^{\star \star \star}$ & $0 \cdot 14$ \\
\hline Food expenditure (1000 rials/month) & 3184 & 121 & $2176^{\star \star \star}$ & 143 & $1982^{\star \star \star}$ & 135 & $1618^{\star \star \star}$ & 161 \\
\hline Clothing expenditure (1000 rials/month) & 644 & 59 & $278^{\star \star \star}$ & 44 & $255^{\star \star *}$ & 46 & $234^{\star \star \star}$ & 52 \\
\hline Rent expenditure (1000 rials/month) & 2523 & 334 & 1650 & 330 & 1978 & 396 & 1392 & 278 \\
\hline $\begin{array}{l}\text { Water, electricity, gas and telephone expenditure } \\
\text { (1000 rials/month) }\end{array}$ & 693 & 47 & $437^{\star \star \star}$ & 41 & $429^{\star \star}$ & 47 & $392^{\star *}$ & 46 \\
\hline Educational expenditure (1000 rials/month) & 940 & 134 & 549 & 245 & 495 & 266 & $154^{*}$ & 42 \\
\hline Leisure-time expenditure (1000 rials/month) & 555 & 108 & $159^{*}$ & 47 & $89^{*}$ & 39 & $22^{\star *}$ & 8 \\
\hline Transfer expenditure (1000 rials/month) & 193 & 24 & 134 & 26 & 163 & 29 & $74^{*}$ & 19 \\
\hline Other expenditure (1000 rials/month) & 208 & 58 & 168 & 39 & 122 & 32 & 420 & 180 \\
\hline Total expenditure (1000 rials/month) & 7481 & 513 & $4730^{\star \star \star}$ & 496 & $4934^{\star \star}$ & 431 & $3755^{\star \star \star}$ & 337 \\
\hline Monthly income (from employment) (1000 rials/month) & 9410 & 778 & $4801^{\star \star \star}$ & 489 & $4486^{\star \star *}$ & 433 & $3755^{\star \star \star}$ & 337 \\
\hline Other income (1000 rials/month) & 1542 & 492 & 344 & 143 & 312 & 141 & 263 & 124 \\
\hline
\end{tabular}

Mean values were significantly different from those of food-secure households: ${ }^{\star} P<0.05,{ }^{\star \star} P<0.01,{ }^{\star \star \star} P<0.001$.

Table 2 Socio-economic characteristics of Tehranian households based on their food security status ( $n$ 416)

\begin{tabular}{|c|c|c|c|c|c|c|c|c|}
\hline \multirow[b]{2}{*}{ Socio-economic variable } & \multicolumn{2}{|c|}{ Food security } & \multicolumn{2}{|c|}{ Mild insecurity } & \multicolumn{2}{|c|}{ Moderate insecurity } & \multicolumn{2}{|c|}{ Severe insecurity } \\
\hline & $n$ & $\%$ & $n$ & $\%$ & $n$ & $\%$ & $n$ & $\%$ \\
\hline \multicolumn{9}{|l|}{ Gender of the head } \\
\hline Male & 214 & $91 \cdot 5$ & 67 & $91 \cdot 8$ & 56 & $93 \cdot 3$ & 40 & $81 \cdot 6$ \\
\hline Female & 20 & 8.5 & 6 & 8.2 & 4 & $6 \cdot 7$ & 9 & $18 \cdot 4$ \\
\hline \multicolumn{9}{|l|}{ Marital status of the head } \\
\hline Married & 216 & $92 \cdot 3$ & 67 & $91 \cdot 8$ & 56 & $93 \cdot 3$ & 40 & $81 \cdot 6$ \\
\hline Widowed & 14 & $6 \cdot 0$ & 6 & $8 \cdot 2$ & 4 & $6 \cdot 7$ & 8 & $16 \cdot 3$ \\
\hline Divorced & 3 & $1 \cdot 3$ & 0 & 0.0 & 0 & $0 \cdot 0$ & 1 & $2 \cdot 0$ \\
\hline Unmarried & 1 & $0 \cdot 4$ & 0 & 0.0 & 0 & 0.0 & 0 & 0.0 \\
\hline \multicolumn{9}{|l|}{ Educational level of the head } \\
\hline Illiterate & $8^{\star \star \star}$ & $3 \cdot 4$ & 6 & $8 \cdot 2$ & 5 & $8 \cdot 3$ & 8 & $16 \cdot 3$ \\
\hline Primary & 25 & $10 \cdot 7$ & 25 & $34 \cdot \overline{2}$ & 14 & $23 \cdot 3$ & 12 & $24 \cdot 5$ \\
\hline Secondary & 63 & $26 \cdot 9$ & 20 & $27 \cdot 4$ & 27 & $45 \cdot 0$ & 20 & $40 \cdot 8$ \\
\hline High-school diploma or higher & 138 & $59 \cdot 0$ & 22 & $30 \cdot 1$ & 14 & $23 \cdot 3$ & 9 & $18 \cdot 4$ \\
\hline \multicolumn{9}{|l|}{ Occupation of the head } \\
\hline Unemployed, student, housekeeper & $25^{\star \star \star}$ & $10 \cdot 8$ & 8 & $11 \cdot 0$ & 3 & $5 \cdot 0$ & 12 & $24 \cdot 5$ \\
\hline Labourer, farmer, animal husbandry & 23 & 9.9 & 17 & $23 \cdot 3$ & 16 & $26 \cdot 7$ & 12 & $24 \cdot 5$ \\
\hline Freelancer, shopkeeper, driver & 72 & $31 \cdot 0$ & 35 & $47 \cdot 9$ & 30 & $50 \cdot 0$ & 20 & $40 \cdot 8$ \\
\hline Employee, teacher/tutor & 79 & $34 \cdot 1$ & 11 & $15 \cdot 1$ & 11 & $18 \cdot 3$ & 4 & $8 \cdot 2$ \\
\hline Manager, doctor, pilot, employer & 33 & $14 \cdot 2$ & 2 & $2 \cdot 7$ & 0 & 0.0 & 1 & $21 \cdot 0$ \\
\hline \multicolumn{9}{|l|}{ Possession of house } \\
\hline Private ownership & 156 & $66 \cdot 7$ & 43 & 58.9 & 28 & $46 \cdot 7$ & 27 & $55 \cdot 1$ \\
\hline Rent & 60 & $25 \cdot 6$ & 26 & $35 \cdot 6$ & 23 & $38 \cdot 3$ & 19 & $38 \cdot 8$ \\
\hline For work & 4 & $1 \cdot 7$ & 1 & $1 \cdot 4$ & 4 & $6 \cdot 7$ & 0 & 0.0 \\
\hline Free of cost & 12 & $5 \cdot 1$ & 3 & $4 \cdot 1$ & 5 & $8 \cdot 3$ & 3 & $6 \cdot 1$ \\
\hline
\end{tabular}

Values were significantly different from those of food-insecure households: ${ }^{\star \star \star} P<0.001$.

and that they 'eat foods they really do not want' at least sometimes.

On the basis of exploratory factor analysis, nine questions of HFIAS loaded into two factors: the first five questions on factor 1 loaded as 'mild-to-moderate FI' and the last four on factor 2 as 'severe FI'. In total, both factors explained $65 \%$ of the variance in responses (Table 6). Eigenvalues $>1.3$ were considered as significant.

Cronbach's $\alpha$ was estimated as 0.855 (95\% CI $0 \cdot 837$, $0 \cdot 888$ ) for all nine questions, which indicates satisfactory internal consistency. A significant correlation was observed between the two administrations of the questionnaire $(r=0 \cdot 895, P<0 \cdot 001)$.

\section{Discussion}

On the basis of our findings, the adapted HFIAS showed acceptable levels of internal consistency, criterion validity and reliability for assessing household FI in Tehran. 
Table 3 Food security status in relation to possession of different facilities in Tehranian households $(n$ 416)

\begin{tabular}{|c|c|c|c|c|c|c|c|c|}
\hline \multirow[b]{2}{*}{ Facilities available in the household } & \multicolumn{2}{|c|}{ Food security } & \multicolumn{2}{|c|}{ Mild insecurity } & \multicolumn{2}{|c|}{ Moderate insecurity } & \multicolumn{2}{|c|}{ Severe insecurity } \\
\hline & $n$ & $\%$ & $n$ & $\%$ & $n$ & $\%$ & $n$ & $\%$ \\
\hline Motorcycle & 30 & $12 \cdot 8$ & 10 & $13 \cdot 7$ & 12 & $20 \cdot 0$ & 10 & $20 \cdot 4$ \\
\hline Cell phone & $219^{* *}$ & $93 \cdot 2$ & 68 & $93 \cdot 2$ & 55 & $91 \cdot 7$ & 38 & $77 \cdot 6$ \\
\hline Automatic washing machine & $187^{\star * \star}$ & $79 \cdot 6$ & 35 & $47 \cdot 9$ & 32 & $53 \cdot 3$ & 23 & $46 \cdot 9$ \\
\hline Semi-automatic washing machine & $37^{\star}$ & $15 \cdot 7$ & 16 & $21 \cdot 9$ & 18 & $30 \cdot 0$ & 16 & $32 \cdot 7$ \\
\hline Vacuum cleaner & $227^{\star}$ & $96 \cdot 6$ & 64 & $87 \cdot 7$ & 53 & $88 \cdot 3$ & 45 & $91 \cdot 8$ \\
\hline Video/compact disc player & $162^{\star \star \star}$ & $68 \cdot 9$ & 35 & $47 \cdot 9$ & 25 & $41 \cdot 7$ & 26 & $53 \cdot 1$ \\
\hline Freezer & $189^{* *}$ & $80 \cdot 4$ & 51 & $69 \cdot 9$ & 41 & $68 \cdot 3$ & 29 & $59 \cdot 2$ \\
\hline Oven & $171^{\star \star \star}$ & $72 \cdot 8$ & 44 & $60 \cdot 3$ & 33 & $55 \cdot 0$ & 22 & 44.9 \\
\hline Stove & $60^{\star \star \star}$ & $25 \cdot 5$ & 29 & $39 \cdot 7$ & 27 & $45 \cdot 0$ & 25 & $51 \cdot 0$ \\
\hline Radio/tape recorder & $147^{\star}$ & $62 \cdot 6$ & 38 & $52 \cdot 1$ & 29 & $48 \cdot 3$ & 22 & $44 \cdot 9$ \\
\hline Computer & $157^{\star}$ & $66 \cdot 8$ & 26 & $35 \cdot 6$ & 26 & $43 \cdot 3$ & 17 & $34 \cdot 7$ \\
\hline Internet & $71^{\star \star *}$ & $30 \cdot 2$ & 8 & $11 \cdot 0$ & 7 & $11 \cdot 7$ & 7 & $14 \cdot 3$ \\
\hline Car & $156^{\star \star \star}$ & $66 \cdot 4$ & 35 & $47 \cdot 9$ & 25 & $41 \cdot 7$ & 17 & $34 \cdot 7$ \\
\hline
\end{tabular}

*Values were significantly different between groups: ${ }^{*} P<0.05,{ }^{* *} P<0.01,{ }^{* \star *} P<0.001$.

Table 4 Mean and SE of consumed food groups and nutrient intakes of adult female participants in Tehranian households by food-security status

\begin{tabular}{|c|c|c|c|c|c|c|c|c|}
\hline \multirow[b]{2}{*}{ Food groups and nutrients } & \multicolumn{2}{|c|}{ Food secure (n 233) } & \multicolumn{2}{|c|}{ Mildly insecure ( $n$ 73) } & \multicolumn{2}{|c|}{ Moderately insecure $(n 60)$} & \multicolumn{2}{|c|}{ Severely insecure ( $n$ 49) } \\
\hline & Mean & SE & Mean & SE & Mean & SE & Mean & SE \\
\hline Bread and cereals $(\mathrm{g})$ & $304 \cdot 5$ & $9 \cdot 4$ & $353 \cdot 0^{*}$ & $16 \cdot 8$ & $330 \cdot 1$ & $17 \cdot 1$ & $366 \cdot 1^{\star *}$ & $19 \cdot 8$ \\
\hline Legumes $(\mathrm{g})$ & $59 \cdot 3$ & $4 \cdot 2$ & $82 \cdot 8^{*}$ & $10 \cdot 7$ & $80 \cdot 5^{\star}$ & $9 \cdot 6$ & $77 \cdot 9$ & $12 \cdot 4$ \\
\hline Vegetables $(\mathrm{g})$ & $227 \cdot 7$ & $8 \cdot 5$ & $244 \cdot 1$ & $18 \cdot 5$ & $198 \cdot 8$ & $16 \cdot 3$ & $202 \cdot 7$ & $18 \cdot 7$ \\
\hline Fruit (g) & $266 \cdot 3$ & $11 \cdot 5$ & $214 \cdot 2^{* \prime} \dagger$ & $17 \cdot 3$ & $202 \cdot 4^{\star} \dagger$ & $15 \cdot 4$ & $291 \cdot 3$ & $52 \cdot 4$ \\
\hline Meat (g) & $71 \cdot 2$ & $2 \cdot 9$ & $68 \cdot 5$ & $6 \cdot 3$ & $66 \cdot 5$ & $5 \cdot 9$ & $57 \cdot 6$ & $4 \cdot 8$ \\
\hline Eggs (g) & $42 \cdot 4$ & $2 \cdot 2$ & $49 \cdot 7 \dagger$ & $3 \cdot 2$ & $47 \cdot 3$ & $2 \cdot 9$ & $37 \cdot 3$ & $5 \cdot 2$ \\
\hline Milk and dairy products $(\mathrm{g})$ & $283 \cdot 3$ & $13 \cdot 0$ & $271 \cdot 7$ & $23 \cdot 1$ & $250 \cdot 5$ & $20 \cdot 2$ & $213 \cdot 7^{\star}$ & $31 \cdot 2$ \\
\hline Fats and oils (g) & $25 \cdot 4$ & $1 \cdot 2$ & $30 \cdot 0$ & $2 \cdot 5$ & $30 \cdot 3^{\star \star}$ & $3 \cdot 1$ & $31 \cdot 2$ & $3 \cdot 5$ \\
\hline Sugar (g) & $21 \cdot 6$ & $1 \cdot 1$ & $23 \cdot 4$ & $2 \cdot 0$ & $20 \cdot 1$ & $1 \cdot 7$ & $27 \cdot 0^{*}$ & $2 \cdot 8$ \\
\hline Energy $(\mathrm{kJ})$ & $1595 \cdot 9$ & $36 \cdot 6$ & $1746 \cdot 2$ & $73 \cdot 4$ & $1633 \cdot 2$ & $73 \cdot 3$ & $1746 \cdot 3$ & $103 \cdot 7$ \\
\hline Carbohydrate (g) & 234.9 & $5 \cdot 6$ & $262 \cdot 1^{*}$ & $11 \cdot 0$ & $240 \cdot 4$ & $10 \cdot 3$ & $268 \cdot 8^{*}$ & $13 \cdot 8$ \\
\hline Protein $(\mathrm{g})$ & $52 \cdot 9$ & $1 \cdot 2$ & $55 \cdot 0$ & $2 \cdot 2$ & $53 \cdot 6$ & $2 \cdot 1$ & $52 \cdot 5$ & $2 \cdot 8$ \\
\hline Fat $(\mathrm{g})$ & $51 \cdot 4$ & $1 \cdot 6$ & $55 \cdot 2$ & $3 \cdot 5$ & $52 \cdot 6$ & $3 \cdot 6$ & $53 \cdot 3$ & $5 \cdot 4$ \\
\hline $\mathrm{Ca}(\mathrm{mg})$ & $694 \cdot 3$ & $18 \cdot 8$ & $662 \cdot 5$ & $33 \cdot 1$ & $630 \cdot 0$ & $31 \cdot 7$ & $598 \cdot 1$ & $39 \cdot 5$ \\
\hline $\mathrm{Fe}(\mathrm{mg})$ & $10 \cdot 0$ & 0.3 & $10 \cdot 7$ & 0.5 & $10 \cdot 4$ & 0.5 & $10 \cdot 9$ & $0 \cdot 8$ \\
\hline Thiamin (mg) & $1 \cdot 29$ & 0.03 & $1 \cdot 44^{*}$ & 0.06 & $1 \cdot 33$ & 0.06 & $1 \cdot 49^{*}$ & 0.09 \\
\hline Riboflavin (mg) & $1 \cdot 15$ & 0.03 & $1 \cdot 10$ & 0.05 & 1.05 & 0.04 & 1.02 & 0.06 \\
\hline Niacin $(\mathrm{mg})$ & $16 \cdot 2$ & $0 \cdot 4$ & $17 \cdot 3$ & $0 \cdot 7$ & $16 \cdot 4$ & $0 \cdot 7$ & $18 \cdot 1^{*}$ & $1 \cdot 1$ \\
\hline Vitamin C (mg) & 111.9 & $4 \cdot 4$ & $96 \cdot 8$ & $7 \cdot 7$ & $87 \cdot 7^{\star \star}$ & $6 \cdot 4$ & $86 \cdot 9^{*}$ & $9 \cdot 2$ \\
\hline Vitamin A ( $\mu \mathrm{g} R E)$ & $658 \cdot 2$ & $34 \cdot 7$ & $573 \cdot 0$ & $42 \cdot 5$ & $455 \cdot 4^{\star \star}$ & $30 \cdot 3$ & $551 \cdot 8$ & $67 \cdot 1$ \\
\hline Retinol (mg) & $1790 \cdot 6$ & $77 \cdot 2$ & $1536 \cdot 5$ & $91 \cdot 7$ & $1364 \cdot 6^{\star *}$ & $97 \cdot 9$ & $1558 \cdot 6$ & $181 \cdot 0$ \\
\hline
\end{tabular}

$R E$, retinol equivalents.

Mean values were significantly different from those of food-secure households: ${ }^{\star} P<0.05,{ }^{\star *} P<0 \cdot 01$.

Mean values were significantly different from those of severely food-insecure households: $+P<0.05$.

FI based on HFIAS in Tehran was related to residency in middle- and low-SES districts, to lower educational level and job status of the household head, to lower income and expenditures and to lower possession of most household facilities. Consumption of bread, cereals, legumes, sugar and, marginally, fats and oils, as well as carbohydrate and thiamin intakes of women in food-insecure households, was higher than that of food-secure households. In contrast, intakes of fruit, milk and dairy products (and, marginally, meat), as well as those of vitamins $\mathrm{C}$ and $\mathrm{A}$, were higher in food-secure households than in others. Cronbach's $\alpha$ and factor analysis also confirmed the internal consistency of the adapted questionnaire applied for measuring FI in Iran. According to the survey conducted,
$43.7 \%$ of the studied population suffers from some degree of FI. This figure is similar to that of other studies conducted using instruments based on the perceptional method in other parts of $\operatorname{Iran}^{(19,20,23-27)}$.

Intense testing of HFSSM has confirmed the conceptual framework and ability to measure $\mathrm{FI}^{(7,9,21)}$. Additional research has shown the validity and reliability of this tool in minority groups (i.e. Asian and Pacific Islanders in Hawaii and Latinos in California). The HFSSM has shown its ability to address the availability of nutritionally adequate food, although certain aspects were not entirely valid with subgroups of Samoans, suggesting that the instrument is not necessarily appropriate for use in all cultural groups ${ }^{(8,28)}$. FI as measured by the HFSSM 
Table 5 Responses of Tehranian households to nine questions included in the HFIAS

\begin{tabular}{|c|c|c|c|c|c|c|c|c|}
\hline \multirow[b]{3}{*}{ HFIAS questions } & \multicolumn{8}{|c|}{ Options } \\
\hline & \multicolumn{2}{|c|}{ No } & \multicolumn{2}{|c|}{ Rarely } & \multicolumn{2}{|c|}{ Sometimes } & \multicolumn{2}{|c|}{ Often } \\
\hline & $n$ & $\%$ & $n$ & $\%$ & $n$ & $\%$ & $n$ & $\%$ \\
\hline Q1: Worry about food & 317 & $76 \cdot 0$ & 50 & $12 \cdot 0$ & 33 & $7 \cdot 9$ & 17 & $4 \cdot 1$ \\
\hline Q2: Unable to eat preferred foods & 273 & $65 \cdot 5$ & 77 & $18 \cdot 5$ & 44 & $10 \cdot 6$ & 23 & $5 \cdot 5$ \\
\hline Q3: Eat just a few kinds of foods & 308 & 73.9 & 50 & $12 \cdot 0$ & 44 & $10 \cdot 6$ & 15 & $3 \cdot 6$ \\
\hline Q4: Eat foods they really do not want to eat & 307 & $73 \cdot 6$ & 57 & $13 \cdot 7$ & 47 & $11 \cdot 3$ & 6 & $1 \cdot 4$ \\
\hline Q5: Eat a smaller meal & 357 & $85 \cdot 6$ & 34 & $8 \cdot 2$ & 21 & $5 \cdot 0$ & 5 & $1 \cdot 2$ \\
\hline Q6: Eat fewer meals in a day & 381 & $91 \cdot 4$ & 19 & $4 \cdot 6$ & 12 & $2 \cdot 9$ & 5 & $1 \cdot 2$ \\
\hline Q7: No food of any kind in the household & 380 & $91 \cdot 1$ & 21 & $5 \cdot 0$ & 15 & $3 \cdot 6$ & 1 & 0.2 \\
\hline Q8: Go to sleep hungry & 393 & $94 \cdot 2$ & 17 & $4 \cdot 1$ & 5 & $1 \cdot 2$ & 2 & 0.5 \\
\hline Q9: Go a whole day and night without eating & 408 & $97 \cdot 8$ & 8 & $1 \cdot 9$ & 1 & $0 \cdot 2$ & 0 & 0.0 \\
\hline
\end{tabular}

HFIAS, Household Food Insecurity Access Scale.

Table 6 Factor loadings for rotated component matrix for households' responses to nine questions included in the HFIAS in Tehran (higher factor loadings are indicated in bold font)

\begin{tabular}{lcc}
\hline HFIAS questions & Factor 1 (moderate food insecurity) & Factor 2 (severe food insecurity) \\
\hline Q2: Unable to eat preferred foods & $\mathbf{0 . 8 6 4}$ & 0.150 \\
Q3: Eat just a few kinds of foods & $\mathbf{0 . 8 1 5}$ & 0.277 \\
Q1: Worry about food & $\mathbf{0 . 7 9 6}$ & 0.140 \\
Q4: Eat foods they really do not want to eat & $\mathbf{0 . 7 8 2}$ & 0.225 \\
Q5: Eat a smaller meal & $\mathbf{0 . 5 3 5}$ & 0.474 \\
Q9: Go a whole day and night without eating & -0.001 & $\mathbf{0 . 8 3 1}$ \\
Q8: Go to sleep hungry & 0.269 & $\mathbf{0 . 8 0 2}$ \\
Q7: No food of any kind in the household & 0.233 & $\mathbf{0 . 6 8 8}$ \\
Q6: Eat fewer meals in a day & 0.372 & $\mathbf{0 . 6 7 4}$
\end{tabular}

HFIAS, Household Food Insecurity Access Scale.

Extraction method: principal component analysis, rotation method: Varimax with Kaiser normalization.

Kaiser-Meyer-Olkin measure of sampling adequacy $=0.85$.

Bartlett's test of sphericity, approximate $\chi^{2}=1746 \cdot 6(P<0 \cdot 001)$.

includes shortages of food, unsuitability of food and the preoccupation with continuing access to food, and is initially characterized by decreased amounts and varieties of food. Food-insecure households generally consume less meat and milk, which is directly related to payday ${ }^{(29,30)}$. Low female educational level and large family size are also shown to be associated with increased hunger ${ }^{(31)}$.

In Latin America, the first study on a tool similar to the HFSSM in Venezuela ${ }^{(32)}$ revealed that assessment of predictors of energy availability and self-perceived household FI may be a reliable way to identify and monitor food security in peri-urban homes. In a second phase of the study, PLAN (Planification Local de la Agricultura y la Naturaleza - Community Planning for Sustainable Livestock-based Forested Ecosystems) ${ }^{(33)}$, an adapted version of the HFSSM was applied in several rural communities located in Ecuador and Mexico. FI captured the conceptual framework of hunger and related aspects such as household food stores and money spent on food in Ecuador. In Mexico, FI was significantly and inversely correlated with the number of food items in the household, as well as with animalsource foods, dairy products, processed foods, fruit, vegetables and dietary variety ${ }^{(34)}$.

In 2003 in Bolivia, a statistically significant correlation was found between expenditure per capita per day and food security status measured by an adapted version of the HFSSM that excluded those items related to the children in the household ${ }^{(35)}$. In the study conducted in the city of Campinas, Brazil, Pérez-Escamilla et al. ${ }^{(36)}$ found significantly negative correlations between daily intakes of fruit, vegetables, meat or fish and dairy products and FI.

Factor analysis of the resulting data from a study conducted in Colombia ${ }^{(37)}$ showed that, similar to the present study, the scale discriminates at least two components: (i) FI without hunger; and (ii) FI with hunger. When analysed using Rasch modelling by Pérez-Escamilla et al. $^{(38)}$ and Hackett et al. ${ }^{(39)}$, all items in both Brazil and Colombia showed infit values within a range of $0 \cdot 8$ and $1 \cdot 2$, which is considered adequate for this scale. The scale used showed highly significant associations with food availability, begging, children's labour and household size. In the Caribbean islands of Trinidad and Tobago, FI was inversely associated with monthly household income and educational level of mothers ${ }^{(40)}$.

In 2008, Knueppel ${ }^{(41)}$ tested the construct validity, internal consistency and convergent validity of the HFIAS in measuring household FI in rural Tanzania. Two main factors emerged from the rotated principal component factor analysis: (i) insufficient food quality; and (ii) insufficient food intake. Both factors explained $69 \%$ of the total variance. 
The full FI scale and the two subscales had good internal consistency (Cronbach's $\alpha=0 \cdot 83-0 \cdot 90$ ), which is similar to that of the present study. Food security was positively associated with maternal and husband's education, household wealth status, being of an agricultural rather than pastoral tribe and animal-source food consumption; it was negatively associated with maternal age and household size. Earlier in 2005, Leyna et al. ${ }^{(42)}$ had shown that the Radimer/Cornell FI measure had significant associations with selected sociodemographic factors in expected directions in rural Tanzania.

In two studies in Canada, which comprised low-income single mothers and a sample of Toronto women seeking charitable food aid, researchers found that higher levels of household FI were associated with social isolation or activity, limiting health conditions, older maternal age, smaller community size and financial insecurity ${ }^{(43)}$. In foodinsecure households, as defined by HFSSM, grains, dairy, fruit and vegetables and meat were consumed less ${ }^{(44)}$.

Recently, Deitchler et al. ${ }^{(6)}$ examined empirically the extent to which the objectives of internal, external and cross-cultural validity of HFIAS have been achieved. They used seven HFIAS data sets collected in diverse contexts and from different countries such as Mozambique (two data sets), Malawi, West Bank/Gaza Strip, Kenya, Zimbabwe and South Africa and applied statistical methods based on the Rasch measurement model. Although the results from their empirical analyses showed several scales to have reasonable internal validity for some data sets, not all scales tested showed internal validity for all data sets. On the basis of these findings, they have proposed a three-item scale (including items 7, 8 and 9 of the HFIAS); however, the advantage of this recent scale to HFIAS in the Iranian community is unclear and needs further assessment.

Three studies in Iran considered FI questionnaire validation using three different questionnaires. In the study by Dastgiri et al. ${ }^{(19)}$ conducted in the north-west region of Iran, the sensitivity, specificity and accuracy of the short questionnaire for screening for hunger in the population according to the $24 \mathrm{~h}$ dietary recall were $98.7 \%$, $85.5 \%$ and $89 \%$, respectively, and the corresponding values for hidden hunger were $23.5 \%, 96.9 \%$ and $56 \cdot 3 \%$. As we can see, sensitivity of this questionnaire is not high for hidden hunger.

Zerafati et al. ${ }^{(18)}$ in 2003 assessed the applicability, validity and reliability of the adapted Radimer/Cornell questionnaire to measure FI in a culturally different context of low-income urban households in district 20 of Tehran. Three scales, labelled as household, individual and child hunger, were extracted through factor analysis. Internal consistency of the scales was 0.897, 0.820 and 0.796, respectively. Individual insecurity and child hunger were inversely correlated with monthly per capita income, father's and mother's education and father's occupational status, and were positively correlated with the size of the household. However, household insecurity did not follow the same pattern. Consumption frequency of fruit, vegetables, dairy, red meat and rice declined as FI status worsened, whereas bread and potato consumption increased. Thus, further modifications seemed necessary to measure FI at the household level. In the present study, many associations were observed between household FI and socio-economic variables, except for family size, age, sex and marital status of the household head. Most of our sample comprised married men-headed households and there did not exist a huge difference between households with regard to family size and age of the household head.

The consumption of bread, cereals, legumes, sugar and, marginally, fats and oils of food-insecure households was higher than that of food-secure households. Because most of the carbohydrate and thiamin intakes in Iranian households come from bread and cereals, intakes of these two nutrients were higher in food-insecure households as well. In contrast, fruit, milk and dairy products (and, marginally, meat) and intakes of vitamins $\mathrm{C}$ and A were higher in food-secure households. Previous studies in Iran, which mainly based their definition of FI on energy intake $<90 \%$ of requirements, have shown that low nutrient density is not entirely an income-driven issue and is much more prevalent than low energy intake ${ }^{(13-17)}$. Although there is a sharp income dependence of the household food basket in terms of quality, other factors such as educational level of the head and his spouse, as well as family size, affect the diet quality of households ${ }^{(15)}$. In addition, the dietary profile of Iranians over the last two decades has been influenced by major policies, including untargeted subsidies for dietary energy and food prices ${ }^{(14)}$. On the basis of such an analysis, energy intake alone is not a good indicator of FI in Iran ${ }^{(45)}$.

Rafiei et al. ${ }^{(20)}$ assessed the internal validity of the adapted US HFSSM to measure FI among adults and children in Isfahan, Iran, using the Rasch measurement model. Data were provided by 2004 randomly selected households during 2005. In all, $53 \cdot 1 \%$ of households reported that their food had run out at some time during the previous 12 months and that they had not had money to buy more, whereas $26.7 \%$ reported that an adult had reduced the size of a meal or skipped a meal and $7 \cdot 2 \%$ reported that an adult had not eaten for a whole day because there had not been enough money for food. Similar figures in our data were $14.4 \%$ for eating smaller meals, $8.6 \%$ for eating fewer meals in a day and $2 \cdot 1 \%$ for going a whole day and night without eating. Infit statistics of most items were near unity, and none exceeded 1.20. Both scales (child and adult) showed acceptable levels of internal validity, although several items should be improved. Specifically, adult items AD1, AD3, AD4 and AD7 and child items $\mathrm{CH} 1, \mathrm{CH} 2, \mathrm{CH} 4$ and $\mathrm{CH} 6$ may benefit from further examination using qualitative methods. Researchers in the FANTA Project have recommended the Rasch model 
to develop household food security surveys and evaluate the psychometric characteristics of their items. The Rasch model provides a theoretical statistical framework for inferring the associations of items with a latent trait based on the observed associations among the items.

The similarity of household FI experiences ranging from worry to adaptations or coping methods with regard to the quantity and quality of food allows for the tool to be easily adjusted to a global audience. The adaptation of the USdeveloped HFSSM or FANTA-developed HFIAS appears to perform well under many circumstances in various regions of the world. Most of the previous validation studies in Iran pointed to the fact that further improvements are required before using the instruments. The HFIAS has generated considerable interest throughout the developing world and has already been adapted as a national food security tool in some countries. There is an urgent need in Iran to establish a rapid, simple and low-cost tool for the screening of FI at the national level. In the present study, the application of adapted HFIAS is considered a strength because of the fact that it is basically designed for developing countries. It is the first time that this instrument is being applied to assess FI in the city of Tehran. However, many difficulties emerged while conducting the present study, including lack of trained nutritionists for conducting consumption surveys, which led to a lot of time being spent in preparing a team. On the basis of our findings, it can be concluded that the adapted HFIAS used in the present study is an appropriate tool that can be introduced in the country's Food Insecurity and Vulnerability Information and Mapping System (see http://www.fivims.org) to provide information on the foodinsecure and vulnerable population and assist in evidencebased analysis in order to advocate for the formulation and implementation of policies and programmes enhancing food security and nutrition.

\section{Acknowledgements}

The present study was funded by the National Nutrition and Food Technology Research Institute (NNFTRI), Faculty of Nutrition Sciences and Food Technology, Shahid Beheshti University of Medical Sciences. The authors have no conflict of interest to declare. F.M. and N.O. contributed to all phases of the research as a $\mathrm{PhD}$ candidate and supervisor, respectively; A.H.-R., M.R.-K. and M.A. contributed to gathering and analysing data, especially dietary intake data; Y.M. was the statistic counsellor. The authors are grateful to the Dean and personnel of NNFTRI. The authors thank all interviewers and participants of the Measurement and Modeling of Household Food Security in Urban Households in the City of Tehran project. They also thank Dr Ghassemi, Dr Gail Harrison, Megan Deitchler and her co-workers in the Food and Nutrition Technical Assistance II Project (FANTA-2) for their valuable comments.

\section{References}

1. The World Bank (1986) Poverty and Hunger Issues and Options for Food Security in Developing Countries. Washington, DC: World Bank Policy Study.

2. United States Agency for International Development (1992) Policy Determination 19, Definition of Food Security. Washington, DC: USAID.

3. Maxwell S \& Frankenberger TR (1992) Household Food Security: Concepts, Indicators and Measurements (A Technical Review). New York and Rome: UNICEF and IFAD.

4. Babu SC \& Sanyal P (2009) Food Security, and Nutrition Policy Analysis: Statistical Methods and Applications. Burlington, MA: Elsevier.

5. Coates J, Swindale A \& Bilinsky P (2006) Housebold Food Insecurity Access Scale (HFIAS) for Measurement of Food Access: Indicator Guide. Washington, DC: FANTA Project, AED.

6. Deitchler M, Ballard T, Swindale A et al. (2010) Validation of a Measure of Housebold Hunger for Cross-Cultural Use. Washington, DC: FANTA-2, AED.

7. Tarasuk V (2001) Discussion Paper on Household and Individual Food Insecurity. Ottawa: Health Canada; available at http://www.hc-sc.gc.ca/fn-an/nutrition/pol/food_ sec_entire-sec_aliments_entier-eng.php

8. Derrickson J, Fisher A \& Anderson J (2000) The core food security module scale measure is valid and reliable when used with Asians and Pacific Islanders. J Nutr 130, 2666-2674.

9. Frongillo EA (1999) Validation of measures of food insecurity and hunger. J Nutr 129, 2 S Suppl., 506S-509S.

10. Hamilton W, Cook J, Thompson W et al. (1997) Household Food Security in the United States in 1995: Summary Report of the Food Security Measurement Project. Washington, DC: USDA.

11. Kendall A, Olson C \& Frongillo E (1995) Validation of the Radimer/Cornell measures of hunger and food insecurity. J Nutr 125, 2793-2801.

12. Carlson S, Andrews M \& Bickel G (1999) Measuring food insecurity and hunger in the United States: development of a national benchmark measure and prevalence estimates. J Nutr 129, 2S Suppl., 510S-516S.

13. Ghassemi H (1998) Food and Nutrition Security in Iran: A National Study on Planning and Administration. Tehran: Plan and Budget Organization.

14. Ghassemi H, Harrison G \& Mohammad K (2002) An accelerated nutrition transition in Iran. Public Health Nutr 4, 149-155.

15. Ghassemi H, Kimiagar M \& Koupahi M (1996) Food and Nutrition Security in Tebran Province. Tehran: NNFTRI.

16. Kalantari N, Ghaffarpoor M, Houshyar-Rad A et al. (2005) National Comprehensive Study on Household Food Consumption Patterns and Nutritional Status of I.R. Iran, 2001-2003. Tehran: NNFTRI, SBMU, Ministry of Health.

17. Pajouyan J (2005) Comprehensive Study on Nutritional Practise and Food Security of Iranian Households. Tehran: Commercial Studies and Researches Foundation.

18. Zerafati-Shoae N, Omidvar N, Ghazi-Tabatabaie $\mathrm{M}$ et al. (2007) Is the adapted Radimer/Cornell questionnaire valid to measure food insecurity of urban households in Tehran, Iran? Public Health Nutr 10, 855-861.

19. Dastgiri S, Tutunchi H, Ostadrahimi A et al. (2007) Sensitivity and specificity of a short questionnaire for food insecurity surveillance in Iran. Food Nutr Bull 28, 55-58.

20. Rafiei M, Nord M, Sadeghizadeh A et al. (2009) Assessing the internal validity of a household survey-based food security measure adapted for use in Iran. Nutr J 8, 28-38.

21. Melgur-Quinonez H \& Hackett M (2008) Measuring household food security: the global experience. Rev Nutr Campinas 21, Suppl., 27S-37S. 
22. Coates J, Frongillo EA, Rogers BL et al. (2006) Commonalities in the experience of Household Food Insecurity across cultures: what are measures missing? I Nutr 136 issue 5, 1438S-1448S.

23. Dastgiri S, Mahboob S, Tutunchi H et al. (2006) Determinants of food insecurity: a cross-sectional study in Tabriz. J Ardabil Univ Med Sci Health Serv 3, 233-239.

24. Dorosty AR, Karamsoltani Z, Jazayeri A et al. (2008) Association between obesity, food security and related family factors. I School Public Health Institute Public Health Res 1, 1-9.

25. Karam-soltani Z, Dorosty-motlagh A, Eshraghian $\mathrm{M}$ et al. (2007) Obesity and food security in Yazd primary school students. Tehran Univ Med J 7, 68-76.

26. Mohammadzadeh A, Dorosty A \& Eshraghian M (2010) Household food security status and associated factors among high-school students in Esfahan, Iran. Public Health Nutr 13, 1609-1613.

27. Ramesh T, Dorosty-Motlagh A \& Abdollahi M (2010) Prevalence of household food insecurity in the City of Shiraz and its association with socio-economic and demographic factors, 2008. Iranian J Nutr Sci Food Tech 4, 53-64.

28. Harrison GG, Stormer A, Herman DR et al. (2003) Development of a Spanish-language version of the US Household Food Security Survey Module. I Nutr 133, 1192-1197.

29. Dixon L, Winkleby M \& Radimer K (2001) Dietary intakes and serum nutrients differ between adults from foodinsufficient and food-sufficient families: Third National Health and Nutrition Examination Survey, 1988-1994. J Nutr 131, 1232-1246.

30. Hamelin A, Beaudry M \& Baict J (2002) Characterization of food insecurity in Quebec: food and feelings. Soc Sci Med 54, 119-132.

31. Olson C (1999) Nutrition and health outcomes associated with food insecurity and hunger. J Nutr 129, 2S Suppl., 521S-524S.

32. Lorenzana P \& Mercado C (2005) Measuring household food security in poor Venezuelan households. Public Health Nutr 5, 851-857.

33. Hackett M, Melgar-Quiñonez H, Zubieta A et al. (2007) Food security and household food supplies in rural Ecuador. Arch Latinoam Nutr 57, 10-17.
34. Melgar-Quinonez H, Zubieta A, Valdez E et al. (2005) Validation of an instrument to monitor food insecurity in Sierra de Manantlan, Jalisco. Salud Publica Mex 47, 413-422.

35. Melgar-Quinonez HR, Zubieta AC, MkNelly B et al. (2006) Household food insecurity and food expenditure in Bolivia, Burkina Faso, and the Philippines. J Nutr 136, issue 5, 1431S-1437S.

36. Perez-Escamilla R, Segall-Correa A, Kurdian Maranha L et al. (2004) An adapted version of the U.S. Department of Agriculture food insecurity module is a valid tool for assessing household food insecurity in Campinas, Brazil. J Nutr 134, 1923-1928.

37. Álvarez M, Estrada A, Montoya E et al. (2006) Validation of a household food security scale in Antioquia, Colombia. Salud Publica Mex 48, 474-481.

38. Melgar-Quinonez H, Nord M, Pérez-Escamilla R et al. (2008) Psychometric properties of a modified US-household food security survey module in Campinas, Brazil. Eur J Clin Nutr 62, 665-673.

39. Hackett M, Melgar-Quinonez H \& Uribe MCA (2008) Internal validity of a household food security scale is consistent among diverse populations participating in a food supplement program in Colombia. BMC Public Health 8, 175-183.

40. Gulliford MC, Nunes C \& Rocke B (2006) The 18 Household Food Security Survey items provide valid food security classifications for adults and children in the Caribbean. BMC Public Health 6, 26-33.

41. Knueppel D, Demment M \& Kaiser L (2010) Validation of the Household Food Insecurity Access Scale in rural Tanzania. Public Health Nutr 13, 360-367.

42. Leyna GH, Mmbaga EJ, Mnyika KS et al. (2007) Validation of the Radimer/Cornell food insecurity measure in rural Kilimanjaro, Tanzania. Public Health Nutr 11, 684-689.

43. McIntyre L, Glanville N, Officer S et al. (2002) Food insecurity of low-income lone mothers and their children in Atlantic Canada. Can J Public Health 93, 411-415.

44. Tarasuk V (2001) Household food insecurity with hunger is associated with women's food intakes, health and household circumstances. J Nutr 131, 2670-2676.

45. Mohammadi F, Omidvar N, Houshiar-Rad A et al. (2008) Association of food security and body weight status of adult members of Iranian households. Iranian J Nutr Sci Food Tech 2, 41-53. 